\title{
Exploring the Loneliness and Internet Addiction Level of College Students Based on Demographic Variables
}

\author{
Osman Erol \\ Mehmet Akif University, Turkey \\ ORCID: 0000-0002-9920-5211 \\ Nese Sevim Cirak \\ Mehmet Akif University, Turkey \\ ORCID: 0000-0002- 5843-6291
}

\begin{abstract}
The aim of this study is to examine the loneliness and Internet addiction levels of college students in terms of demographic variables and to determine the variables that predict their Internet addiction level. Data were collected from college students studying at a public university in Turkey. The UCLA Loneliness Scale Version3 and Internet Addiction Test (IAT) were used as the data collection tools. College students were delivered an online survey and at the end 489 college students were voluntarily participated in the study. This survey study employed independent sample t-tests, ANOVA tests, correlation and multiple regression tests for data analysis. The results show that younger participants felt significantly more loneliness than older participants; similarly, students in lower classes felt more alone than those in upper classes. In terms of addiction, it is seen that the frequent use of computers, smartphones and social media increases the Internet addiction level of students. The study suggests a significant correlation between loneliness, Internet addiction, age, and Cumulative Grade Point Average (CGPA). Additionally, loneliness and CGPA significantly predict Internet addiction. This study may be important in terms of determining the psychological variables affecting today's increasing technology addiction (internet, smart phone, etc.). Thus, determining the effect of the level of loneliness of young people on internet addiction may be effective in terms of preventing this addiction.
\end{abstract}

Keywords: Internet addiction; Loneliness; UCLA Loneliness Scale; Internet Addiction Test

\section{Introduction}

The Internet was developed in the 1969's and since then improved and grown rapidly to became an important part of daily life (Chou et al., 2015) for various ages and gender groups. However, the rapid increase of Internet usage causes issues such as problematic use of the Internet (Kim \& Davis, 2009) and Internet addiction (Block, 2008). Although the Internet provides various social networking and entertainment opportunities, it is also seen that the number of users who use the Internet excessively for work, and for social networking and/or entertainment are increasing (Chou et al., 2015). The overuse and compulsive use of the Internet might negatively impact the psychological, physical and social well-being of a person (Davis, 2001; Young, 1998). 
Ivan Goldberg provided the first definition of Internet Addiction Disorder (IAD) in 1995 in order to describe the diagnostic criteria for the Overuse of Internet (Goldberg, 1996). Internet addiction, which is also called Pathological Internet Use, describes the situation in which a person is unable to control their Internet usage and faces psychological, social or work difficulties (Chou et al., 2015) as a consequence. It is a physical condition in which a person is negatively affected emotionally and mentally by excessive use of the Internet (Beard, 2005). Internet addiction is a behavioral control problem (Young \& Abreu, 2011). In other words, the Internet users are unable to control their Internet usage which as a result might lead to problems in their daily life (Shek, Sun, \& Yu, 2013) such as skipped meals, lack of sleep, harm done to their educational and professional careers, or damage to their family relationships (Kardefelt-Winther, 2014). Due to the large volume of research and the high demand for clinical treatment, the American Psychiatric Association (APA, 2012) has added "Internet Gaming Disorder" in Section III of the Fifth Edition of the "Diagnostic and Statistical Manual for Mental Disorders (DSM-5)" (Holden, 2010; Yao \& Zhong, 2014).

Griffiths (1998) claims that Internet addiction can be seen as a kind of technological addiction and a subset of behavioral addiction. Likewise, according to Kandell (1998), Internet addiction is "a psychological dependence on the Internet, regardless of the type of activity once logged on" (p. 12). Many researchers have attempted to diagnose the clinical criteria of Internet overuse (Dowling \& Quirk, 2009; Tao et al., 2010; Young, 1996, 1998, 1999). But despite attempts, there is no consensus on the diagnostic criteria of IAD (Kardefelt-Winther, 2014; Mitchell, 2000). The literature includes many psychopathological definitions that attempt to describe the phenomenon of unhealthy and excessive use of the Internet (Caplan, 2003; Davis, 2001; Widyanto \& Griffiths, 2006) such as Internet Addiction Disorder, Excessive Internet Use, Pathological Internet Use, Internet Usage Disorder, Compulsive Internet Use, Internet Dependence, Problematical Internet Use, Unregulated Internet Usage etc.

In addition, there is an argument about the research on Internet addiction. Kardefelt-Winther (2014) claims there is no explanation about what causes Internet addiction. Young (1998) indicated that the Internet itself does not yield Internet addiction, but the usage patterns take on an important role in the development of Internet use. It is claimed that instead of focusing on Internet addiction, particular activities performed on the Internet should be examined since people do not become addicted to a specific medium, they become addicted to the specific activities such as online gambling, or social applications (online chatting, social networking sites) (Kuss, Griffiths, \& Binder, 2013). The studies about Internet addiction in the literature also point out that usage of the Internet for chatting, pornography, gambling, and digital gaming etc. might be factors for the development of Internet addiction (Chang \& Law, 2008; Chen, Chen, \& Paul, 2001; Everhard, 2000; Henderson, 2001; Jang, Hwang, \& Choi, 2008; Yang, Choe, Baity, Lee, \& Cho, 2005; Young, 1996). Personality also plays a significant role in Internet addiction as well as the performing of specific online activities. It has been claimed that people who score high on neuroticism (Dong, Wang, Yang, \& Zhou, 2013), and low on emotional stability, agreeableness and extraversion (van der Aa et al., 2009) are tended towards Internet addiction. In addition, according to some researchers, gender is a significant factor in Internet addiction, with male students more likely to become Internet addicts than female students (Chou \& Hsiao, 2000; Leung \& Lee, 2012; Tsai et al., 2009). This is contrary to other research that showed gender as not affecting Internet addiction levels (Chou et al., 2015).

The numbers of people who exhibit problems regulating their Internet usage are increasing (Muusses, Finkenauer, Kerkhof, \& Billedo, 2014). People suffering from Internet addiction display several symptoms; displaying behavioral and cognitive preoccupation with the Internet 
(Van den Eijnden, Meerkerk, Vermulst, Spijkerman, \& Engels, 2008), not having control over their Internet use, and withdrawal symptoms when they are unable to use the Internet (Muusses et al., 2014). Those with Internet addiction can develop several comorbid psychological symptoms (Dong, Lu, Zhou, \& Zhao, 2011) such as developing low self-esteem, isolating themselves from social life, (Bernardi \& Pallanti, 2009; Kim, \& Haridakis, 2009; Yen, Ko, Yen, Wu, \& Yang, 2007), hyperactivity, and problems with attention persistence (Griffiths, 2012). In addition, they may develop a variety of problematic behaviors (Jiang, \& Leung, 2012) such as aggression (Ko, Yen, Liu, Huang, \& Yen, 2009), impulsivity (Lee et al., 2012), and seeking out novelty and sensation (Ko et al., 2009; Park et al., 2013).

Internet addicts are unable to limit their Internet use; they continue to use the Internet despite problems they face both academically and socially due to their excessive Internet use, and feel anxious when their Internet access is limited (Shapira et al., 2003). Skipping work or academic studies due to computer use, separating themselves from their real-life friends in order to be with online friends are also mentioned as consequences of excessive Internet usage (Fu, Chan, Wong, \& Yip, 2010; Yen, Yen, Chen, Chen, \& Ko, 2007). Also, studies have shown that Internet addiction can be associated with low self-esteem, social phobias, depression, anxiety, and difficulties in a school or work environment (Young, 2007).

Chou and Hsiao (2000) warned that overuse of the Internet might lead to health and time management problems, as well as creating problems for users in conducting their daily activities or communicating and interacting with others around them. People who suffer from problematic Internet usage spend excessive amounts of their time on the Internet which negatively affects their daily life activities; and concerning their online activities, they exhibit a need to escape into cyberspace, and feel nervous when they try to decrease their Internet use (Dell'Osso, Altamura, Allen, Marazziti, \& Hollander, 2006). Additionally, their marital or family relationships may suffer, their job productivity may decrease or they may even lose their job, show poor performance at academic studies and face failure as a result of excessive Internet use (Chou \& Hsiao, 2000). Young (1998) showed that overuse of the Internet led to problems in family life due to some users having cyber-affairs that harmed their real-life relationships.

Kim, LaRose, and Peng (2009) demonstrated that people who were lonely and did not develop good social skills can develop compulsive Internet usage behaviors which prevents them from the building of healthy social relationships and interactions in their daily life, and therefore feel an increased sense of loneliness. In a study that employed Coping Orientation to Problems Experienced (COPE), it was seen that those who suffered from Internet addiction significantly gained higher scores on the measure of mental and behavioral disengagement than nonaddicts. Additionally, Internet addicts significantly use instrumental social support and emotional social support, suppress competing in activities and planning, and show positive growth and reinterpretation at a lower level than those without Internet addiction (Tonioni et al., 2014). It has been shown that poor coping strategies might cause people to have more stress, exhibit negative patterns of behavior, develop psychosomatic symptoms and lowered academic performance (Yussuf, Issa, Ajiboye, \& Buhari, 2013). Internet addiction leads to the development of symptoms of anxiety, social phobias and depression after a period of two years (Gentile et al., 2011). Similarly, depression, social phobia, hostility, attention-deficit or hyperactivity might be considered as symptoms of Internet addition also after a period of two years (Ko, Yen, Chen, Yeh, \& Yen, 2009).

Studies have shown that Internet addiction correlates positively with psychosocial problems like loneliness and depression (Beard, 2005; Ha et al., 2007; Tokunaga \& Rains, 2010), and is 
related with deficiencies in social and psychological functioning (Canan, Ataoglu, Ozcetin, \& Icmeli, 2012; Ko et al., 2009). Moreover, associations are reported between loneliness, depression and Internet addiction (Gamez-Guadix, Villa-George, \& Calvete, 2012; LaRose, Lin, \& Eastin, 2003; Munoz-Rivas, Fernandez, \& Gamez-Guadix, 2010; Odaci \& Kalkan, 2010).

Kim et al. (2009) found that loneliness could both be the cause and effect of problematic use of Internet among American college students. Similarly, Yen, Ko, Yen, Chang, and Cheng (2009) conducted a research with 8,941 Taiwanese adolescents and indicated that lack of familial contact and depression were discriminating factors for Internet addiction. Similarly, Tokunaga and Rains (2010) examined 94 studies conducted in 22 countries and their meta-analysis proved a correlation between depression, loneliness, and Internet addiction. Yao and Zhong (2014) also showed a correlation between the loneliness, depression and Internet overuse and found that it increases the sense of loneliness. According to the researchers, using online interaction with family and friends is less effective compared to offline interactions in reducing feelings of loneliness. Moreover, the increment in online interactions due to excessive Internet use might neutralize the positive effects of offline interactions in reducing Internet addiction symptoms. The researchers concluded that there is a worrisome vicious cycle between Internet addiction and loneliness.

It is proven that some people prefer the Internet in order to cope with negative feelings such as loneliness, sadness or anxiousness (Munoz-Rivas et al., 2010), or to deal with psychological problems (Morahan-Martin \& Schumacher, 2000). But, whereas usage of the Internet may help users to deal with depression, anxiety, stress or loneliness, they might then become Internet addicts due to relief provided by the Internet in overcoming their initial problems. This situation has the potential to cause Internet addiction (LaRose et al., 2003). Ozdemir, Kuzucu, and Ak (2014) investigated the effects of loneliness and depression on Internet addiction with 648 Turkish undergraduate students. They found that loneliness had a significantly stronger relationship with Internet addiction than depression. They concluded that loneliness was a more important factor in Internet addiction compared to depression and claimed that lonely people were more likely to use the Internet for social interaction than people with depression.

It has been shown that lonely people are likely to spend most of their time on the Internet (Amichai-Hamburger \& Ben-Artzi, 2003) since it creates a social environment in which they can interact with other people (Morahan-Martin \& Schumacher, 2000). Caplan (2002) investigated the effects of loneliness, self-esteem, shyness, and depression on Internet addiction and found that only loneliness had a significant relationship with problematic Internet use. In their study with 398 adults, Muusses et al. (2014) found that compulsive Internet usage increased symptoms of loneliness, stress, depression, and decreased levels of happiness; also, that happiness prevented excessive Internet usage over time. Similarly, people who suffer from Internet addiction are found to be lonely, less happy, stressed and depressed and develop lower self-esteem (Byun et al., 2009; Tokunaga \& Rains, 2010). Muusses et al. (2014) stated that there was a negative correlation between wellbeing and compulsive Internet use, and that compulsive Internet usage increased levels of depression, stress, and loneliness, whereas, over time, happiness and self-esteem decreased with compulsive Internet use.

Students intending to use the Internet for academic purposes such as research and communication has resulted in the Internet having taken on an important role in their daily life (Chou, \& Hsiao, 2000), and that they use it for various purposes such as entertainment and socialization. Widyanto and Griffiths (2006) identified students as an at-risk population for 
several reasons. First of all, they have a high interest in Internet usage (Veen \& Vrakking, 2006) and that their high levels of Internet literacy are linked to Internet addiction (Leung \& Lee, 2012). Especially university students are at risk as they have the opportunity for free and unlimited Internet access, free from parental control and interference, have flexible schedules (Kuss et al., 2013) so that their online activities are not controlled externally within the university setting, their university encourages them to use the Internet, and the university setting might make them socially frustrated and frightened (Young, 2004).

When the studies are examined, it is seen that internet addiction is a global problem that especially young individuals are affected seriously. Hence, the psychological variables that push them to use internet excessively should be investigated. In other words, it is important to examine the psychological factors that might cause internet addiction. Therefore, the aim of the current study is to examine the Internet addiction levels of college students in terms of certain variables and to determine variables that predict Internet addiction. In this context, answers to the following research questions are sought:

- What is the loneliness level of college students?

- Is there any significant difference between college students' loneliness level in terms of gender, age, class level, frequency of daily computer and smartphone usage and use of social media?

- What is the Internet addiction level of college students?

- How do college students' Internet behaviors change according to level of Internet addiction?

- Is there any significant difference between college students' Internet addiction level in terms of gender, age, class level, frequency of daily computer and smartphone usage and use of social media?

- Is there a significant relationship between college students' Internet addiction levels, loneliness levels, Cumulative Grade Point Average (CGPA), and age?

- Do the levels of loneliness, CGPA and age significantly predict Internet addiction of college students?

\section{Methodology}

\section{Design of the Study}

In this quantitative study, survey method was implemented in order to assess the loneliness and Internet addiction levels of the college students. Since survey method can be applied to describe or understand the behaviors, characteristics, beliefs, attitudes of the population by applying questions to the population or sample (Creswell, 2009; Fraenkel, Wallen, \& Hyun, 2012), the survey method was believed to be the method most suited for the current study.

\section{Participants of the Study}

Data of the study were collected from college students registered to a public university located in the Mediterranean region of Turkey. The participants in this study are 489 college students, 
$56.9 \%(n=278)$ of whom are female and $43.1 \%(n=211)$ male, who ranged in age from 17 to $26(M=20.54 ; S D=1.60)$ years. Data were collected across all class levels, with $36.5 \%(n=177)$ as freshmen, $23.9 \%(n=116)$ as sophomores, $22.5 \%(n=109)$ as juniors, and $17.1 \%(n=84)$ as senior students. Table 1 details the participants' demographic characteristics.

Table 1.Demographics of the Participants

\begin{tabular}{llrl}
\hline & & $n$ & $\%$ \\
\hline Gender & Female & 278 & 56.9 \\
Faculty & Male & 211 & 43.1 \\
& Education & 290 & 59.8 \\
Class Levels & Other & 199 & 40.2 \\
& Freshmen & 177 & 36.5 \\
& Sophomores & 116 & 23.9 \\
& Juniors & 109 & 22.5 \\
& Senior & 84 & 17.1 \\
\hline
\end{tabular}

\section{Data Collection Instruments}

In this study, a questionnaire was used to collect data. The questionnaire was divided into three parts. In the first part, there were six questions regarding the demographics of the participants which were age, gender, CGPA, class level, the frequency of technology use, and the purpose of their Internet use. The second part includes the UCLA Loneliness Scale Version 3, which was tested and validated by Russell (1996). The scale has 20 items that measure the loneliness level of the undergraduate students. Cronbach's Alpha reliability coefficient for this scale was found to be .834 . The four-point, Likert-type scale had options ranging from 1 (Never) to 4 (Always). In the scale, higher grades represent a higher level of loneliness. In the last part of the questionnaire, Young's (1998) Internet Addiction Test (IAT) was included. The scale contains 20 five-point, Likert type items ranging from 1 (Rarely) to 5 (Always). The scores gained from the questionnaire represents the participant's level of addiction. Scores between 20 and 39 indicate a normal level of Internet use, whereas 40 to 69 implies potential Internet addiction, and 70 to 100 represents Internet addiction. Cronbach's Alpha reliability coefficient for this test was calculated as .903.

\section{Data Collection Process and Analysis}

The questionnaire prepared for this study was delivered to the college students in printed form. Prior to the questionnaire's distribution, the students were informed about the aim of the study and ensured that their responses would be used only for academic purposes and that their identity would not be revealed. Then, they were kindly asked whether or not they wanted to participate on a voluntary basis. The questionnaire took ten to fifteen minutes to complete. The collected data were then coded through IBM SPSS Statistics 21 package program. Inferential statistics were applied in order to analyze the data collected in the study. Independent sample t-tests, ANOVA tests, correlation and multiple regression tests were conducted in order to answer the research questions of the study. All the assumptions of the tests were checked and ensured that they were met before applying the tests. 


\section{Findings}

Based on the research questions, the findings of the study are presented in three subtitles which are "Loneliness Level of the Participants", "Internet Addiction Level of the Participants" and "Correlation and Regression Test Results." Corresponding interpretation for each finding is presented after the Tables.

\section{Loneliness Level of the Participants}

Loneliness level of the participants were examined according to various variables such as gender, age, class level, frequency of daily computer and smartphone usage and use of social media and the results are presented in Table 2 and Table 3.

Table 2. Results of t-test and Descriptive Statistics for Loneliness

\begin{tabular}{llcrrrr}
\hline Variable & & $\mathrm{N}$ & $\mathrm{M}$ & $\mathrm{SD}$ & $\mathrm{t}$ & $\mathrm{p}$ \\
\hline \multirow{2}{*}{ Gender } & Female & 278 & 38.41 & 10.03 & -.98 & .33 \\
& Male & 211 & 39.29 & 9.41 & & \\
Social Media Usage & Occasionally & 166 & 39.27 & 9.14 & .75 & .45 \\
& Very often & 323 & 38.57 & 10.08 & & \\
Age (years) & $\leq 20$ & 259 & 39.78 & 10.21 & 2.34 & .02 \\
& $>20$ & 230 & 37.72 & 9.14 & & \\
\hline
\end{tabular}

The study showed that only $15.1 \%$ of the participants $(n=74)$ gained higher loneliness scores, whereas $84.9 \%$ of them $(n=415)$ gained lower scores. Independent sample $t$ tests were applied to the data in order to find out whether or not the participants' loneliness levels significantly differed in terms of their gender, social media usage, or age (Table 2). The data showed that the participants in this study developed low loneliness levels, and that males $(M=39.29, S D=9.41)$ did not significantly differ from females $(M=38.41, S D=10.03$, $\mathrm{p}>=.05)$. Similarly, the participants who occasionally used it did not significantly differ between participants who used it very often. However, when the participants' loneliness score were analyzed based on their age, it was seen that participants who were 20-year-old or younger $(M=39.78, S D=10.21)$ significantly differed from participants who were older than $20(M=37.72, S D=9.14)$. In other words, the younger participants felt loneliness significantly more than the older participants $(t(487)=2.347, p<.05)$.

Table 3. Results of ANOVA tests and Descriptive Statistics for Loneliness

\begin{tabular}{llrrrrrr}
\hline Variable & & $\mathrm{N}$ & $\mathrm{M}$ & $\mathrm{SD}$ & $\mathrm{F}$ & $\mathrm{p}$ & Posthoc* \\
\hline Daily PC usage & $<1$ hour & 253 & 38.80 & 9.85 & .018 & .98 & \\
& $1-3$ hours & 127 & 38.89 & 9.87 & & & \\
& $>3$ hours & 97 & 38.64 & 9.54 & & & \\
Daily use of smartphones & $<3$ hours & 128 & 38.76 & 9.11 & 1.88 & .15 & \\
& $3-5$ hours & 147 & 40.03 & 9.77 & & & \\
& $>5$ hours & 214 & 38.00 & 10.10 & & &
\end{tabular}




\begin{tabular}{llrrrrrr} 
Class Level (grade) & 1 & 179 & 39.70 & 10.37 & 3.37 & .019 & $1-4$ \\
& 2 & 117 & 39.12 & 9.38 & & & \\
& 3 & 109 & 39.35 & 9.62 & & & \\
\multirow{4}{*}{ Internet Addiction } & 4 & 84 & 35.79 & 8.69 & & & \\
& None & 384 & 37.83 & 9.56 & 10.78 & .00 & $1-2$ \\
& At risk & 89 & 43.06 & 9.77 & & & \\
& Addicted & 16 & 38.80 & 8.78 & & & \\
\hline
\end{tabular}

In addition, ANOVA tests were applied to the data to see whether or not the participants differentiated in terms of their daily use of computers and daily use of mobile phones in hours, their class level, and their Internet addiction level, to their loneliness score (Table 3). The data showed that their daily use of computers and smart phones did not significantly affect the participants' loneliness scores. However, when analyzed based on class level, the data showed a significant differences between freshman $(M=39.70, S D=10.37)$ and senior students $(M=35.79, S D=8.69)$ which indicated that freshman felt significantly more lonely compared to seniors. Likewise, it was seen that participants who were prone to Internet addiction $(M=43.06, S D=9.77)$ had significantly higher loneliness scores compared to non-addicted participants $(M=37.83, S D=9.56)$. Table 3 summarizes the results of the ANOVA tests.

\section{Internet Addiction Level of the Participants}

The findings show that majority of the participants $(78.5 \%, n=384)$ were not addicted to the Internet. Only 3.3\% of the participants $(n=16)$ in this study were be considered as Internet Addicts, whereas $18.2 \%$ of them $(n=89)$ were considered at Risk (Table 4$)$.

Table 4. Internet Addiction Level of Participants

\begin{tabular}{crr}
\hline Group & $N$ & $\%$ \\
\hline None & 384 & 78.5 \\
At Risk & 89 & 18.2 \\
Addicted & 16 & 3.3 \\
Total & 489 & 100.0 \\
\hline
\end{tabular}

Internet behaviors of the participants according to their Internet dependency levels were also examined. The findings showed that the participants used the Internet for many purposes such as communication, education, shopping, games and social media (Table 5).

Table 5. Internet Behaviors of Participants According to Level of Internet Addiction

\begin{tabular}{llrrrrrr}
\hline Variable & \multicolumn{1}{c}{ None } & \multicolumn{3}{c}{ At Risk } & \multicolumn{2}{c}{ Addicted } \\
& & $N$ & \multicolumn{1}{c}{$\%$} & \multicolumn{1}{c}{$n$} & \multicolumn{1}{c}{$\%$} & \multicolumn{1}{c}{$n$} & $\%$ \\
\hline Using Internet for & Never & 59 & 12.07 & 11 & 0.20 & 1 & 0.20 \\
communication & Occasionally & 234 & 47.85 & 53 & 10.84 & 9 & 1.84 \\
& Very often & 89 & 12.20 & 24 & 4.91 & 6 & 1.23 \\
Using Internet for & Never & 19 & 3.89 & 10 & 2.05 & 1 & 0.20 \\
Education & Occasionally & 247 & 50.51 & 57 & 11.66 & 14 & 2.87 \\
& Very often & 116 & 23.72 & 22 & 4.499 & 1 & 0.20
\end{tabular}




\begin{tabular}{llrrrrrr} 
Using Internet for & Never & 117 & 23.93 & 24 & 4.91 & 1 & 0.20 \\
Shopping & Occasionally & 229 & 46.83 & 49 & 10.02 & 11 & 2.25 \\
& Very often & 36 & 7.37 & 15 & 3.07 & 4 & 0.82 \\
Using Internet for & Never & 106 & 21.68 & 12 & 2.45 & 1 & 0.20 \\
Gaming & Occasionally & 198 & 40.49 & 46 & 9.41 & 7 & 1.43 \\
& Very often & 79 & 16.16 & 31 & 6.34 & 8 & 1.64 \\
Using Internet for & Occasionally & 141 & 28.83 & 21 & 4.29 & 4 & 0.82 \\
Social media & Very Often & 243 & 49.69 & 68 & 13.91 & 12 & 2.45 \\
Daily PC usage & Never & 211 & 43.15 & 35 & 7.16 & 7 & 1.43 \\
& Occasionally & 102 & 20.86 & 25 & 5.11 & 0 & 0 \\
& Very often & 60 & 12.27 & 28 & 5.73 & 9 & 1.84 \\
Daily mobile phone & Never & 114 & 23.31 & 10 & 2.05 & 4 & 0.82 \\
usage & Occasionally & 124 & 25.36 & 21 & 4.30 & 2 & 0.41 \\
& Very often & 146 & 29.86 & 58 & 11.86 & 10 & 2.045 \\
\hline
\end{tabular}

Independent t-tests were conducted to assess whether or not there were differences between the participants Internet addiction level in terms of gender, age and their use of social media (Table 6). Males $(M=36.6, S D=17.04)$ did not differ significantly from females $(M=35.42$, $S D=17.27)$. Likewise, the participants aged 20 years or younger $(M=36.11, S D=16.17)$ did not significantly differ from those older than 20 years $(M=35.36, S D=17.84)$ in terms of their Internet addiction. However, the participants who used social media very often ( $M=38.7$, $S D=16.93)$ were significantly more addicted to Internet compared to the participants who occasionally used it $(M=30.41, S D=16.77)(t(487)=-5.171, p<.05)$. The results of the tests are given in detail in Table 6.

Table 6. Results of t-test and Descriptive Statistics for Internet Addiction

\begin{tabular}{llrrrrr}
\hline Variable & & $\mathrm{n}$ & $\mathrm{M}$ & $\mathrm{SD}$ & $\mathrm{t}$ & $\mathrm{P}$ \\
\hline Gender & & & & & & \\
& Female & 278 & 35.42 & 17.27 & -.73 & 0.469 \\
Mge (years) & 211 & 36.57 & 17.44 & & \\
& $\leq 20$ & & & & & \\
\multirow{2}{*}{ Social Media Usage } & 20 & 259 & 36.11 & 16.17 & .27 & 0.78 \\
& & 230 & 35.69 & 18.56 & & \\
& & & & & & \\
& Occasionally & 166 & 30.41 & 16.77 & -5.171 & .00 \\
& Very often & 323 & 38.74 & 16.93 & & \\
\hline
\end{tabular}

Similarly, ANOVA tests were conducted to see whether or not the Internet addiction of participants differed in terms of their daily use of computers and mobile phones in hours, and their class level (see Table 7). It was seen that participants who spent more than three hours on a $P C$ each day $(M=43.78, S D=19.10)$ were significantly more Internet addicted than participants who spent less than one hour $(M=33.33, S D=16.59)$ and those who spent between one to three hours $(M=35.31, S D=15.76)$. Likewise, participants who spent less than three hours in a day using their mobile phones $(M=28.35, S D=16.48)$, who spent between three to five hours $(M=34.44, S D=15.58)$, and who spent more than five hours $(M=41.45, S D=17.09)$ were differed significantly from each other. However, the results showed that class level did not affect the participants' Internet addiction level. 
Table 7. Results of ANOVA tests and Descriptive Statistics for Internet Addiction

\begin{tabular}{llrrrrrc}
\hline Variable & $\mathrm{n}$ & $\mathrm{M}$ & $\mathrm{SD}$ & $\mathrm{f}$ & $\mathrm{p}$ & Posthoc* $^{*}$ \\
\hline Daily PC usage & $<1$ hour & 253 & 33.33 & 16.59 & 13.51 & .00 & $1-3$ \\
& $1-3$ hours & 127 & 35.31 & 15.76 & & & $2-3$ \\
& $>3$ hours & 97 & 43.78 & 19.09 & & & \\
Daily use of & $<3$ hours & 128 & 28.35 & 16.48 & 26.13 & .00 & $1-2$ \\
smartphones & $3-5$ hours & 147 & 34.44 & 15.58 & & & $1-3$ \\
& $>5$ hours & 214 & 41.45 & 17.09 & & & $2-3$ \\
Class level (grade) & 1 & 179 & 35.35 & 16.23 & .40 & .75 & \\
& 2 & 117 & 37.31 & 17.04 & & & \\
& 3 & 109 & 36.06 & 17.45 & & & \\
& 4 & 179 & 35.35 & 16.23 & & & \\
\hline
\end{tabular}

\section{Correlation and Regression Test Results}

For the aim of the current study, the correlations between loneliness, Internet addiction, age and CGPA scores were assessed. A Pearson product-moment correlation coefficient was computed to assess the relationships between the variables. Table 8 shows a significant correlation between loneliness and Internet addiction scores $(r=.237, n=489, p=.00)$, loneliness and age $(r=-.106, n=489, p=.020)$, and loneliness and CGPA $(r=-.147, n=489$, $p=.001)$. Similarly, there were significant correlations between Internet addiction scores and CGPA ( $r=-.167, n=489, p=.000)$, and age and CGPA $(r=125, n=489, p=.006)$, whereas there was no correlation between age and Internet addiction scores $(r=-.014, n=489$, $p=.749)$.

Table 8. Correlations between Variables

\begin{tabular}{|c|c|c|c|c|}
\hline Measure & 1 & 2 & 3 & 4 \\
\hline 1. Loneliness & - & $.237^{*}$ & $-.106^{*}$ & $-.147^{*}$ \\
\hline 2. Internet Addiction & $237^{*}$ & - & -.014 & $-.167 *$ \\
\hline 3. Age & $-.106^{*}$ & -.014 & - & $.125^{*}$ \\
\hline 4. CGPA & $-.147 *$ & $-.167^{*}$ & $.125^{*}$ & - \\
\hline
\end{tabular}

In Table 9, the results of the regression analysis are given. When Table 9 is examined, it can be seen that the model which included loneliness levels, grade average, and age significantly predicts the participants' Internet addiction levels $\left(r=.291, R^{2}=.085, F(3-481)=14.862\right.$, $\mathrm{p}<.001)$. Moreover, this model explains about $9 \%$ of the change in the participants' Internet addiction levels. According to the standardized regression coefficients, the relative importance of the predictive variables on Internet addiction are loneliness $(\beta=.222)$, grade average $(\beta=-$ $0.164)$, and age $(\beta=.022)$, respectively. When the significance levels of the regression coefficients are taken into consideration, it is seen that only loneliness $(p=.000)$ and grade average $(p=.000)$ variables are significant predictors of Internet addiction level. 
CONTEMPORARY EDUCATIONAL TECHNOLOGY, 2019, 10(2), XXX-XXX

DOI: hpps://doi.org/10.30935/cet.554488 - TYPE: Research Article

Table 9. Results of Regression Analysis between Loneliness, Grade Average, Age, and Internet Addiction

\begin{tabular}{lrrrrl}
\hline Variable & \multicolumn{1}{c}{ B } & Std. Error & $\beta$ & \multicolumn{1}{l}{$T$} & \multicolumn{1}{l}{$p$} \\
\hline Constant & 31.739 & 11.259 & & 2.819 & 0.005 \\
Loneliness & 0.395 & 0.079 & 0.222 & 5.030 & 0.000 \\
CGPA & -5.661 & 1.532 & -0.164 & -3.696 & 0.000 \\
Age & 0.240 & 0.489 & 0.022 & 0.490 & 0.624 \\
\hline$r=291, \mathrm{R}^{2}=.085, \mathrm{~F}(3-481)=14.862$, & $\mathrm{p}<.001$ & & &
\end{tabular}

$r=.291, R^{2}=.085, F(3-481)=14.862, p<.001$

\section{Discussion and Recommendations}

This study aims to identify the loneliness and Internet addiction level of college students. Moreover, it aims to show the relationship between loneliness, Internet addiction, Cumulative Grade Point Average (CGPA), and age. For this study, college students registered to a public university located in the Mediterranean region of Turkey were delivered an online survey and at the end 489 college students were voluntarily participated to the study.

Gender did not affect the Internet addiction levels of the college students. However, in some studies, it has been reported that males are at risk on Internet addiction (Leung \& Lee. 2012; Tsai et al., 2009). Chou and Hsiao (2000) suggested that gender was one of the most powerful predictors of Internet addiction. Similarly, Chou, Condron, and Belland (2005) claimed that gender had a significant effect on extensive Internet usage. According to the researchers, males are more likely to be Internet addicts than females. However, more recently, Chou et al. (2015) showed that gender did not play a significant role in Internet addiction. The findings of the current study also indicated that gender did not play a significant role in the Internet addiction level of college students.

In addition to Internet addiction, the findings of the current study revealed that gender also did not affect the loneliness level of the college students, which was also indicated by Muusses et al. (2014), who found no significant correlation between gender, happiness, and loneliness. The current study showed that only a few of the participants felt lonely, whereas the majority did not. Especially, college students younger than 21 years old significantly felt lonelier when compared to other aged students. This might have been caused by their adaptation to the university setting. Since they were new to the university, they might not have yet developed strong friendships as they had desired, but later on they might manage to make friends and feel less lonely compared to their first years.

Similarly, the current study found that the use of social media, PCs, and smartphones did not significantly affect the loneliness level of the participants. Since they can stay in contact with their friends and family and reach them whenever they want through social media, they might not feel lonely. However, it was seen that the use of social media, as well as mobile phones and PCs, made a significant difference between the participants in their Internet addiction level. As claimed by several researchers, people do not become addicted to a specific medium. Instead, it is the specific activities such as online gambling, social applications (online chatting and social networking sites) that might lead to addictive behaviors (Chang \& Law, 2008; Chen et al., 2001; Everhard, 2000; Henderson, 2001; Jang et al., 2008; Kuss et al., 2013; Yang et al., 2005; Young, 1996). 
In the current study, the participants who used social media very often were significantly more addicted to the Internet compared to participants who used social media occasionally. Similarly, participants who spent more than three hours on a PC each day were significantly more Internet addicted than the participants who spent less than one hour and those who spent between one and three hours. Participants who spent less than three hours, between three to five hours, more than five hours a day using their mobile phones were significantly different from each other. It is believed that social media might be the cause of the differences between the participants.

Finally, the participants who were at risk of Internet addiction gained significantly higher loneliness scores than non-addicted participants. The literature provides many examples that prove the association between loneliness, depression, and Internet addiction (Beard. 2005; Gamez-Guadix et al., 2012; Ha et al., 2007; LaRose et al., 2003; Munoz-Rivas et al., 2010; Odaci \& Kalkan., 2010; Tokunaga \& Rains, 2010). Yao and Zhong (2014) explained of a worrisome vicious cycle between Internet addiction and loneliness, and Kim et al. (2009) showed that loneliness could be both the cause and effect of problematic of Internet usage among college students in America. People preferred the Internet to cope with negative feelings such as loneliness, anger, and depression (Munoz-Rivas et al., 2010), or to deal with their psychological problems (Morahan-Martin \& Schumacher, 2000). But, when the Internet helped them to deal with these problems, they became more addicted to the Internet due to the relief it provided (LaRose et al., 2003). Similarly, Ozdemir et al. (2014) and Caplan (2002) found that loneliness had a significantly stronger relationship with Internet addiction than depression. Hence, it has been claimed that lonely people are more likely to use the Internet for social interaction (Ozdemir et al., 2014) since it creates a social environment in which to interact with other people (Morahan-Martin \& Schumacher, 2000). Likewise, in the current study, college students who were at risk of Internet addiction might try to interact with other people in an online environment in order to decrease their sense of loneliness; hence they might use the Internet excessively which can lead to Internet addiction.

In the current study, the level of loneliness predicts people's Internet addiction at a low level; however, this rate might increase should similar studies be conducted with adolescents instead of college students. In addition, the current study's sample was selected from only one public university and with participants whose age range was close. Hence, this might affect the measurement of dependent variables such as addiction, and independent variables such as frequency of computer usage and smartphone usage. Therefore, it is suggested to consider these variables when evaluating the results. Also, similar studies could be conducted with college students in different areas of Turkey and with teenagers. In addition to loneliness, different psychological factors that might affect internet addiction such as depression, social support and their relationships should be investigated. Also, qualitative studies should be conducted to determine how these factors leads internet addiction.

\section{References}

American Psychiatric Association (2012). $R 40$ internet use disorder, DSM-5 development. Retrieved on 10 May 2018 from http://www.dsm5.org/ProposedRevision/Pages/ proposedrevision. aspx?rid=573\#

Amichai-Hamburger, Y. \& Ben-Artzi, E. (2003). Loneliness and Internet use. Computers in Human Behavior, 19(1), 71-80. 
Beard, K. W. (2005). Internet addiction: A review of current assessment techniques and potential assessment questions. CyberPsychology and Behavior, 8(1), 7-14.

Bernardi, S. \& Pallanti, S. (2009). Internet addiction: a descriptive clinical study focusing on comorbidities and dissociative symptoms. Comprehensive Psychiatry, 50(6), 510-516.

Block, J. J. (2008). Issues for DSM-V: Internet addiction. American Journal of Psychiatry, 165(3), 306-307.

Byun, S., Ruffini, C., Mills, J.E., Douglas, A.C., Niang, M., Stepchenkova, S., Lee, S.K., Loutfi, J.,Lee, J., Atallah, M. \& Blanton, M. (2009). Internet addiction: metasynthesis of 19962006 quantitative research. CyberPsychology \& Behavior, 12(2), 203-207.

Canan, F., Ataoglu, A., Ozcetin, A. \& Icmeli, C. (2012). The association between Internet addiction and dissociation among Turkish college students. Comprehensive Psychiatry, 53(5), 422-426.

Caplan, S. E. (2002). Problematic internet use and psychosocial well-being: Development of a theory based cognitive behavioral measurement instrument. Computers in Human Behavior, 18(5), 553-575.

Caplan, S. E. (2003). Preference for online social interaction: A theory of problematic Internet use and psychosocial well-being. Communication Research, 30(6), 625-648.

Chang, M. K., \& Law, S. P. M. (2008). Factor structure for young's Internet addiction test: A confirmatory study. Computers in Human Behavior, 24(6), 2597-2619.

Chen, K., Chen, I. \& Paul, H. (2001). Explaining online behavioral differences: an Internet dependency perspective. The Journal of Computer Information Systems, 41(3), 59-64.

Chou, C., Condron, L. \& Belland, J. C. (2005). A review of the research on Internet addiction. Educational Psychology Review, 17(4), 363-388.

Chou, C. \& Hsiao, M. C. (2000). Internet addiction. Usage gratification and pleasure experience: the Taiwan college students' case. Computers \& Education, 35(1), 65-80.

Chou, W. -P., Ko, C. -H., Kaufman, E. A., Crowell, S. E., Hsiao, R. C., Wang, P. -W.,...Yen, C. -F. (2015). Association of stress coping strategies with Internet addiction in college students: The moderating effect of depression. Comprehensive Psychiatry, 62, 27-33.

Creswell, J. W. (2009). Research design: Qualitative, quantitative, and mixed methods approaches (Vol. 4). Thousand Oaks, CA: Sage.

Davis, R. A. (2001). A cognitive-behavioral model of pathological Internet use. Computers in Human Behavior, 17(2), 187-195.

Dell'Osso, B., Altamura, A. C., Allen, A., Marazziti, D. \& Hollander, E. (2006). Epidemiologic and clinical updates on impulse control disorders - A critical review. European. Archives of Psychiatry and Clinical Neuroscience, 256(8), 464-475.

Dong, G., Lu, Q., Zhou, H. \& Zhao, X. (2011).Precursor or sequela: pathological disorders in people with Internet addiction disorder. PloS One, 6(2), 14703.

Dong, G., Wang, J., Yang, X. \& Zhou, H. (2013). Risk personality traits of Internet addiction: A longitudinal study of Internet-addicted Chinese university students. Asia-Pacific Psychiatry, 5(4), 316-321. 
Dowling, N. A. \& Quirk, K. L. (2009). Screening for Internet dependence: Do the proposed diagnostic criteria differentiate normal from dependent Internet use? CyberPsychology \& Behavior, 12(1), 21-27.

Everhard, R. A. (2000). Characteristics of pathological internet users: An examination of on-line gamers (Unpublished doctoral dissertation). Spalding University, Department of Psychology, Louisville, KT.

Fraenkel, J. R., Wallen, N. E. \& Hyun, H. H. (2012). How to design and evaluate research in education (8th ed.). New York: McGraw-Hill.

Fu, K. W., Chan, W. S., Wong, P. W. \& Yip, P. S. (2010). Internet addiction: prevalence. discriminant validity and correlates among adolescents in Hong Kong. The British Journal of Psychiatry, 196(6), 486-492.

Gamez-Guadix, M., Villa-George, F. I. \& Calvete, E. (2012). Measurement and analysis of the cognitive-behavioral model of generalized problematic Internet use among Mexican adolescents. Journal of Adolescence, 35(6), 1581-1591.

Gentile, D. A., Choo, H., Liau, A., Sim, T., Li, D., Fung, D. \& Khoo, A. (2011). Pathological video game use among youths: A two-year longitudinal study. Pediatrics, 127(2), 319-329.

Goldberg, I. (1996), Internet addiction disorder. Retrieved on 30 April 2018 from http://users. rider.edu/ suler/psycyber/supportgp.html

Griffiths, M. (1998). Internet addiction: Does it really exist? In J. Gackenbach (Ed.), Psychology and the Internet: Intrapersonal interpersonal and transpersonal implications. New York: Academic Press.

Griffiths. M. D. (2012). Internet sex addiction: A review of empirical research. Addiction Research \& Theory, 20(2), 111-124.

Ha, J. H., Kim, S. Y., Bae, S. C., Bae, S., Kim, H., Sim, M.,...Cho, S. C. (2007). Depression and Internet addiction in adolescents. Psychopathology, 40(6), 424,430.

Henderson, E. C. (2001). Understanding addiction. Mississippi: University Press of Mississippi.

Holden, C. (2010). Behavioral addictions debut in proposed DSM-V. Science, 327(5968), 935.

Jang, K. S., Hwang, S. Y. \& Choi, J. Y. (2008). Internet addiction and psychiatric symptoms among Korean adolescents. Journal of School Health, 78(3), 165-171.

Jiang, Q. \& Leung, L. (2012). Effects of individual differences, awareness-knowledge and acceptance of Internet addiction as a health risk on willingness to change Internet habits. Social Science Computer Review, 30(2), 170-183.

Kandell, J. J. (1998). Internet addiction on campus: the vulnerability of college students. CyberPsychology and Behavior, 1(1), 11-17.

Kardefelt-Winther, D. (2014). A conceptual and methodological critique of internet addiction research: Towards a model of compensatory internet use. Computers in Human Behavior, 31, 351-354.

Kim, H. K. \& Davis, K. E. (2009). Toward a comprehensive theory of problematic Internet use: Evaluating the role of self-esteem, anxiety, flow and the self-rated importance of Internet activities. Computers in Human Behavior, 25, 450-500. 
Kim, J. \& Haridakis, P. M. (2009). The role of internet user characteristics and motives in explaining three dimensions of internet addiction. Journal of Computer-Mediated Communication, 14(4), 988-1015.

Kim, J., LaRose, R. \& Peng, W. (2009). Loneliness as the cause and the effect of problematic internet use: The relationship between internet use and psychological well-being. Cyberpsychology and Behavior, 12(4), 451-455.

Ko, C.-H., Yen, J.-Y., Chen, C.-S., Yeh, Y.-C. \& Yen. C.-F. (2009). Predictive values of psychiatric symptoms for internet addiction in adolescents: A 2-year prospective study. Archives of Pediatrics \& Adolescent Medicine, 163(10), 937-943.

Ko, C.-H., Yen, J.-Y., Liu, S.-C., Huang, C.-F. \& Yen, C.-F. (2009). The associations between aggressive behaviors and internet addiction and online activities in adolescents. Journal of Adolescent Health, 44(6), 598-605.

Kuss, D. J., Griffiths, M. D. \& Binder, J. F. (2013). Internet addiction in students: Prevalence and risk factors. Computers in Human Behavior, 29(3), 959-966.

LaRose, R., Lin, C. A., and Eastin, M. S. (2003). Unregulated Internet usage: Addiction. habit. or deficient self-regulation? Media Psychology, 5(3), 225-253.

Lee, H. W., Choi, J. S., Shin, Y. C., Lee, J. Y., Jung, H. Y. \& Kwon. J. S. (2012). Impulsivity in internet addiction: a comparison with pathological gambling. CyberPsychology Behavior and Social Networking, 15(7), 373-377.

Leung, L. \& Lee, P. S. N. (2012). The influences of information literacy, internet addiction and parenting styles on internet risks. New Media \& Society, 14(1), 117-136.

Mitchell, P. (2000). Internet addiction: Genuine diagnosis or not? Lancet, 355(9204),632.

Morahan-Martin, J. \& Schumacher, P. (2000). Incidence and correlates of pathological internet use among college students. Computers in Human Behavior, 16(1), 13-29.

Munoz-Rivas, M. J., Fernandez, L. \& Gamez-Guadix, M. (2010). Analysis of the indicators of pathological Internet use in Spanish University students. The Spanish Journal of Psychology, 13(2), 697-707.

Muusses, L. D., Finkenauer, C., Kerkhof, P. \& Billedo, C. J. (2014). A longitudinal study of the association between compulsive internet use and wellbeing. Computers in Human Behavior, 36, 21-28.

Odaci, H. \& Kalkan, M. (2010). Problematic Internet use, loneliness and dating anxiety among young adult university students. Computers and Education, 55(3), 1091-1097.

Ozdemir, Y., Kuzucu, Y. \& Ak, S. (2014). Depression, loneliness and Internet addiction: How important is low self-control? Computers in Human Behavior, 34, 284-290.

Park, S. M., Park, Y. A., Lee, H. W., Jung, H. Y., Lee, J. Y. \& Choi, J. S. (2013). The effects of behavioral inhibition/approach system as predictors of Internet addiction in adolescents. Personality and Individual Differences, 54(1), 7-11.

Russell, D. (1996). The UCLA loneliness scale (Version 3): Reliability, validity and factor structure. Journal of Personality Assessment, 66(1), 20-40.

Shapira, N. A., Lessig, M. C., Goldsmith, T. D., Szabo, S. T., Lazoritz, M., Gold, M. S. \& Stein, D. J. (2003). Problematic internet use: proposed classification and diagnostic criteria. Depression and Anxiety, 17(4), 207-216. 
Shek, D. T. L., Sun, R. C. F., and Yu, L. (2013). Internet addiction. In D. W. Pfaff (Ed.). Neuroscience in the 21st Century: From Basic to Clinical (pp. 2775-2811), New York: Springer.

Tao, R., Huang, X., Wang, J., Zhang, H., Zhang, Y. \& Li, M. (2010). Proposed diagnostic criteria for internet addiction. Addiction, 105(3), 556-564.

Tokunaga, R. S. \& Rains, S. A. (2010). An evaluation of two characterizations of the relationships between problematic Internet use time spent using the Internet and psychosocial problems. Human Communication Research, 36(4), 512-545.

Tonioni, F., Mazza, M., Autullo, G., Cappelluti, R., Catalano, V., Marano, G.,...Lai, C. (2014). Is Internet addiction a psychopathological condition distinct from pathological gambling? Addictive Behaviors, 39(6), 1052-1056.

Tsai, H. F., Cheng, S. H., Yeh, T. L., Shih, C. C., Chen, K. C. \& Yang, Y. C. (2009). The risk factors of Internet addiction - A survey of university freshmen. Psychiatry Research, 167(3), 294299.

Van $\operatorname{der}$ Aa, N., Overbeek, G., Engels, R. C. M. E., Scholte, R. H. J., Meerkerk, G.-J. \& Van den Eijnden, R. J. J. M. (2009). Daily and compulsive Internet use and well-being in adolescence: A diathesis-stress model based on Big Five personality traits. Journal of Youth and Adolescence, 38(6), 765-776.

Van den Eijnden, R. J. J. M., Meerkerk, G. J., Vermulst, A. A., Spijkerman, R., \& Engels, R. C. M. E. (2008). Online communication. Compulsive Internet use and psychosocial well-being among adolescents: A longitudinal study. Developmental Psychology, 44(3), 655-665.

Veen, W. \& Vrakking, B. (2006). Homo sapiens: Growing up in a digital age. London: Network Continuum Education.

Widyanto, L. \& Griffiths, M. (2006). Internet addiction: A critical review. International Journal of Mental Health and Addiction, 4(1), 31-51.

Yang, C. K., Choe, B. M., Baity, M., Lee, J. H. \& Cho, J. S. (2005). Scl-90-r and 16pf profiles of senior high school students with excessive internet use. Canadian Journal of Psychiatry, 50(7), 407-414.

Yao, M. Z. \& Zhong, Z. J. (2014). Loneliness, social contacts and Internet addiction: A crosslagged panel study. Computers in Human Behavior, 30, 164-170.

Yen, C. F., Ko, C. H., Yen, J. Y., Chang, Y. P. \& Cheng, C. P. (2009). Multi-dimensional discriminative factors for Internet addiction among adolescents regarding gender and age. Psychiatry and Clinical Neurosciences, 63(3), 357-364.

Yen, J. Y., Ko, C. H., Yen, C. F., Wu, H. Y. \& Yang, M. J. (2007). The comorbid psychiatric symptoms of Internet addiction: attention deficit and hyperactivity disorder (ADHD), depression, social phobia, and hostility. Journal of Adolescent Health, 41(1), 93-98.

Yen, J. Y., Yen, C. F., Chen, C. C., Chen, S. H. \& Ko, C. H. (2007). Family factors of internet addiction and substance use experience in Taiwanese adolescents. CyberPsychology \& Behavior, 10(3), 323-329.

Young, K. S. (1996). Psychology of computer use: XL. Addictive use of the Internet: A case that breaks the stereotype. Psychological Reports, 79(3), 899-902.

Young, K. S. (1998). Internet addiction: The emergence of a new clinical disorder. CyberPsychology \& Behavior, 1(3), 237-244. 
Young, K. S. (1999). The research and controversy surrounding internet addiction. CyberPsychology \& Behavior, 2(5), 381-383.

Young, K. S. (2004). Internet addiction - A new clinical phenomenon and its consequences. American Behavioral Scientist, 48(4), 402-415.

Young, K. S. (2007). Cognitive behavior therapy with Internet addicts: Treatment outcomes and implications. CyberPsychology \& Behavior, 10(5), 671-679.

Young, K. \& Abreu, C. (2011). Internet addiction. A handbook and guide to evaluation and treatment. Hoboken, NJ: John Wiley \& Sons.

Yussuf, A. D., Issa, B. A., Ajiboye, P. O. \& Buhari, O. I. N. (2013). The correlates of stress, coping styles and psychiatric morbidity in the first year of medical education at a Nigerian University. African Journal of Psychiatry, 16(3), 206-215.

Correspondence: Osman Erol, Assistant Professor, Department of Computer Education and Instructional Technology, Faculty of Education, Mehmet Akif University, Burdur, Turkey 